\title{
Spectral Discrimination of Two Pigweeds from Cotton with Different Leaf Colors
}

\author{
Reginald S. Fletcher ${ }^{1}$, Krishna N. Reddy' ${ }^{1}$ Rickie B. Turley ${ }^{2}$ \\ ${ }^{1}$ Crop Production Systems Research Unit, Agricultural Research Service, United States Department of Agriculture, Stoneville, USA \\ ${ }^{2}$ Crop Genetics Research Unit, Agricultural Research Service, United States Department of Agriculture, Stoneville, USA \\ Email: reginald.fletcher@ars.usda.gov
}

How to cite this paper: Fletcher, R.S., Reddy, K.N. and Turley, R.B. (2016) Spectral Discrimination of Two Pigweeds from Cotton with Different Leaf Colors. American Journal of Plant Sciences, 7, 2138-2150. http://dx.doi.org/10.4236/ajps.2016.715190

Received: September 21, 2016

Accepted: October 25, 2016

Published: October 28, 2016

Copyright (c) 2016 by authors and Scientific Research Publishing Inc. This work is licensed under the Creative Commons Attribution International License (CC BY 4.0).

http://creativecommons.org/licenses/by/4.0/

\begin{abstract}
To implement strategies to control Palmer amaranth (Amaranthus palmeri S. Wats.) and redroot pigweed (Amaranthus retroflexus L.) infestations in cotton (Gossypium hirsutum L.) production systems, managers need effective techniques to identify the weeds. Leaf light reflectance measurements have shown promise as a tool to distinguish crops from weeds. Studies have targeted plants with green leaves. This study focused on using leaf hyperspectral reflectance data to develop spectral profiles of Palmer amaranth, redroot pigweed, and cotton and to determine regions of the light spectrum most sensitive for pigweed and cotton discrimination. The study focused on cotton near-isogenic lines created to have bronze, green, or yellow colored leaves. Reflectance measurements within the 400 to $2500 \mathrm{~nm}$ spectral range were obtained from cotton and weed plants grown in a greenhouse in 2015 and 2016. Two scenarios were evaluated for the comparison: (1) Palmer amaranth versus cotton lines and (2) redroot pigweed versus cotton lines. Statistical significance $(p \leq 0.05)$ was determined with analysis of variance (ANOVA) and Dunnett's test. Sensitivity measurements were tabulated to determine the optimal region of the light spectrum for weed and cotton line discrimination. Optimal bands for weed and cotton separation were 600 to $700 \mathrm{~nm}$ (both weeds versus cotton bronze and cotton yellow), $710 \mathrm{~nm}$ (Palmer amaranth versus cotton green), and $1460 \mathrm{~nm}$ (redroot pigweed versus cotton green). Spectral bands were identified for separating Palmer amaranth and redroot pigweed from cotton lines with bronze, green, and yellow leaves. Ground-based and airborne sensors can be tuned into the regions of spectrum identified, facilitating using remote sensing technology for Palmer amaranth and redroot pigweed identification in cotton production systems.
\end{abstract}

\section{Keywords}

Pigweeds, Cotton Near-Isogenic Lines, Leaf Reflectance 


\section{Introduction}

Cotton growth and productivity in the United States (U.S.) have been negatively impacted by Palmer amaranth and redroot pigweed infestations. Palmer amaranth has reduced cotton yields by $3 \%$ to $88 \%$ in the U.S. [1] [2] [3] [4] [5]. Cotton yield loss by redroot pigweed infestation ranges from $5 \%$ to $90 \%$ depending on plant density and soil pattern [6]. Palmer amaranth and redroot pigweed plants produce thousands of seeds that are dispersed by wind, irrigation water, human, and equipment. Seeds germinate throughout the growing season and without proper management, Palmer amaranth and redroot pigweed outgrow cotton plants and become the dominant plants in a cotton field.

Management practices have been established to control and prevent Palmer amaranth and redroot pigweed infestations. The practices focus on pre-emergence and post-emergence strategies. To implement post-emergent strategies effectively, producers need tools to help them identify the locations of Palmer amaranth and redroot pigweed infestations in cotton fields. Ground survey is the standard method, but is tedious and time consuming. Other tools are needed to expedite Palmer amaranth and redroot pigweed identification in cotton production systems.

Multispectral and hyperspectral reflectance data acquired from plant leaves and canopies have shown good potential for differentiating crops from weeds [7]. Using spectral reflectance measurements of plant leaves and canopies, [8] discriminated five weeds [redroot pigweed, common lambsquarters (Chenopodium album L.) green foxtail ( $S e$ taria viridis L.) Beauv., wild mustard (Sinapis arvensis L.), and wild oat (Avena fatua L.)] and two crops [canola (Brassica napus L.) and spring wheat (Triticum aestivum L.)], [9] distinguished pitted morning glory (Ipomea lacunose L.) from soybean, and [10] differentiated corn caraway (Ridfolia segetum Moris.) from sunflower (Helianthus annuus L.). Researchers have indicated that approximately 15 to 28 non-redundant spectral bands within visible, red edge, near infrared, and shortwave infrared wavelengths are needed for vegetation study, characterization, and mapping [11].

Weed and crop remote sensing studies have focused on plants with green leaves or compared differences between crops and weeds at different phenological stages. Not all cotton plants have green leaves. For example, cotton near-isogenic lines exist that have bronze, green, or yellow leaves. These plants are currently being evaluated at experiment stations and eventually might be grown in fields. Plant phenology may be ineffective for crop weed discrimination, especially if differences occur at times in which weed management would be the least effective.

Currently, no information is available on spectrally discriminating cotton with different leaf colors from Palmer amaranth and redroot pigweed. The objectives of this study were to develop spectral profiles of Palmer amaranth, redroot pigweed, and cotton with leaf hyperspectral reflectance data, and to determine regions of the optical spectrum most sensitive to pigweed and cotton discrimination. The study specifically focused on differentiating the two pigweeds from cotton near-isogenic lines that have bronze, green, or yellow colored leaves. 


\section{Materials and Methods}

\subsection{Experimental Setup}

Greenhouse experiments were conducted in 2015 and 2016 at the United States Department of Agriculture-Agricultural Research Service(USDA-ARS) facility (33.425261 latitude, -90.912740 longitude) in Stoneville, MS. Cotton near-isogenic lines created to have bronze, green, or yellow colored leaves, Palmer amaranth, and redroot pigweed were the plants evaluated in this study. Cotton and weed seeds were obtained from seed banks maintained at the laboratory.

A basic description of the cotton near-isogenic lines is as follows. A backcross breeding method was used to develop near isogenic lines for Bronze Leaf cotton from a conventional upland cotton variety. DP 5690 (Monsanto Company, St. Louis, MO; PVPC 009100116) was selected as the wild-type parent; it was developed into a pure inbred line by self-pollination accompanied by single seed descent (SSD) through nine generations using both greenhouse and field plants grown at the USDA-ARS, Stoneville, MS facility. The Bronze leaf parent, "Bronze Leaf" or Seed Accession 31 (SA 30: PI 528567), has a recessive yellow leaf color trait and was obtained from the Mississippi Obsolete Variety Collection. Pollen from SA 31 was used to fertilize emasculated flowers from the SSD DP 5690 inbred genotype. The $\mathrm{F}_{1}$ seed from each cross was planted in the greenhouse where they were self-fertilized. The $F_{2}$ seed were then planted in the field the following spring and the segregating bronze plants were used in five backcrossing events. Five generations of back-crossed seed $\mathrm{BC}_{1-5} \mathrm{~F}_{2}$ was grown over five consecutive winters and then planted in the field. In the backcross population, pure bronze leaf, yellow leaf, and green leaf were selected and self-pollinated.

Plants were grown in 2-liter plastic pots filled with potting mix (Pro-Mix BX general professional growth medium, Premier Tech Horticulture, Quakertown, PA). Planting dates were May 12, 2015 and May 13, 2016. Plants were subjected to a 14-hr photoperiod; light was provided at the beginning and ending of the day with sodium vapor lamps; the greenhouse temperature was maintained between $21.1^{\circ} \mathrm{C}$ and $26.7^{\circ} \mathrm{C}$. Fertilizer (Dyna-Gro All-Pro 7-7-7, Richmond, CA) and water were added as needed. The experiments consisted of randomized complete block designs with 24 replications to compare the spectral properties of the plants.

\subsection{Leaf Reflectance Measurements}

Leaf reflectance measurements were obtained with a plant contact probe attached to a spectroradiometer (Fieldspec 3, ASD Inc. Boulder, Colorado) sensitive to a spectral rangeof 350 to $2500 \mathrm{~nm}$. The contact probe is equipped with a light source, allowing the analyst to collect data at any time during the day or night. Reflectance measurements were obtained from the most recently matured leaf of each plant. The measurements were acquired by attaching the contact probe to the leaf with a leaf clip (ASD Inc. Boulder, Colorado). Data collection was of the upper leaf surface. Instrument reflectance calibration was completed with a white spectralon (white reference) panel prior to the start of data collection and in 15-min intervals. The instrument's software deter- 
mined reflectance by dividing the data obtained for a sample by the data obtained for the white reference standard. Reflectance measurements were obtained on June 5, 2015 and June 3,2016. The goal of weed management strategies is to detect and kill weeds in vegetative growth stages and prior to seeds reaching full maturity levels. Cotton and Palmer amaranth were in the vegetative growth stages and redroot pigweeds were flowering but had not reached full maturity.

\subsection{Post-Processing of Reflectance Data}

Post-processing of the leaf hyperspectral data was as follows. The 1-nm leaf hyperspectral reflectance data were aggregated to $10 \mathrm{~nm}$ spectral bands to reduce the redundancy in adjacent wavelengths [11] [12]. Data aggregation of the leaf hyperspectral reflectance data was completed with the Gaussian distribution function in the hsdar (hyperspectral data analysis in R) package [13] of the R software [14]. Then, strong absorption and scatter bands (i.e., 350 - $390 \mathrm{~nm}, 1360$ - $1450 \mathrm{~nm}, 1800$ - $1990 \mathrm{~nm}, 2360$ - $2500 \mathrm{~nm}$ ) that cannot be used for plant analysis were extracted from the dataset, resulting in 166 spectral bands available for plant analysis.

\subsection{Statistical Analyses}

Two scenarios were evaluated for statistical analyses: (1) Palmer amaranth versus cotton lines and (2) redroot pigweed versus cotton lines. Statistical analyses included analysis of variance (ANOVA), Dunnett's test, and reflectance sensitivity analysis. ANOVA was used to determine if there was a statistically significant difference $(p \leq 0.05)$ among the groups. For the post-hoc test, the goal was to identify the wavelengths in which a statistically significant difference $(p \leq 0.05)$ was observed between a specific pigweed group and a specific cotton group. The Dunnett's test was used to achieve that goal.

Reflectance sensitivity analysis [15] was tabulated to determine optimal wavelengths for differentiating Palmer amaranth and redroot pigweed from a cotton group. It was calculated by subtracting mean reflectance of a pigweed group from mean reflectance of a cotton group and then dividing the difference by mean reflectance of the pigweed group. Sensitivity values are positive or negative. Negative values occurred when pigweed mean reflectance values were greater than a cotton group mean reflectance values. Increase or decrease in positive and negative values respectively, indicates an increase in the spectral bands potential for weed cotton separation. Spectral regions in which mean differences were determined to be statistically significant based on Dunnett's test results were also deemed statistically significant for the sensitivity results [15]. Statistical analyses were completed with base and multcomp [16] packages of the R software.

\section{Results}

Figure 1(a), Figure 2(a), Figure 3(a), and Figure 4(a) show the mean reflectance curves of the pigweeds and the cotton groups. In the 500 to $700 \mathrm{~nm}$ region of the spectrum, distinct differences were observed in the amplitude of Palmar amaranth and redroot pigweed reflectance curves versus cotton bronze and cotton yellow reflectance 

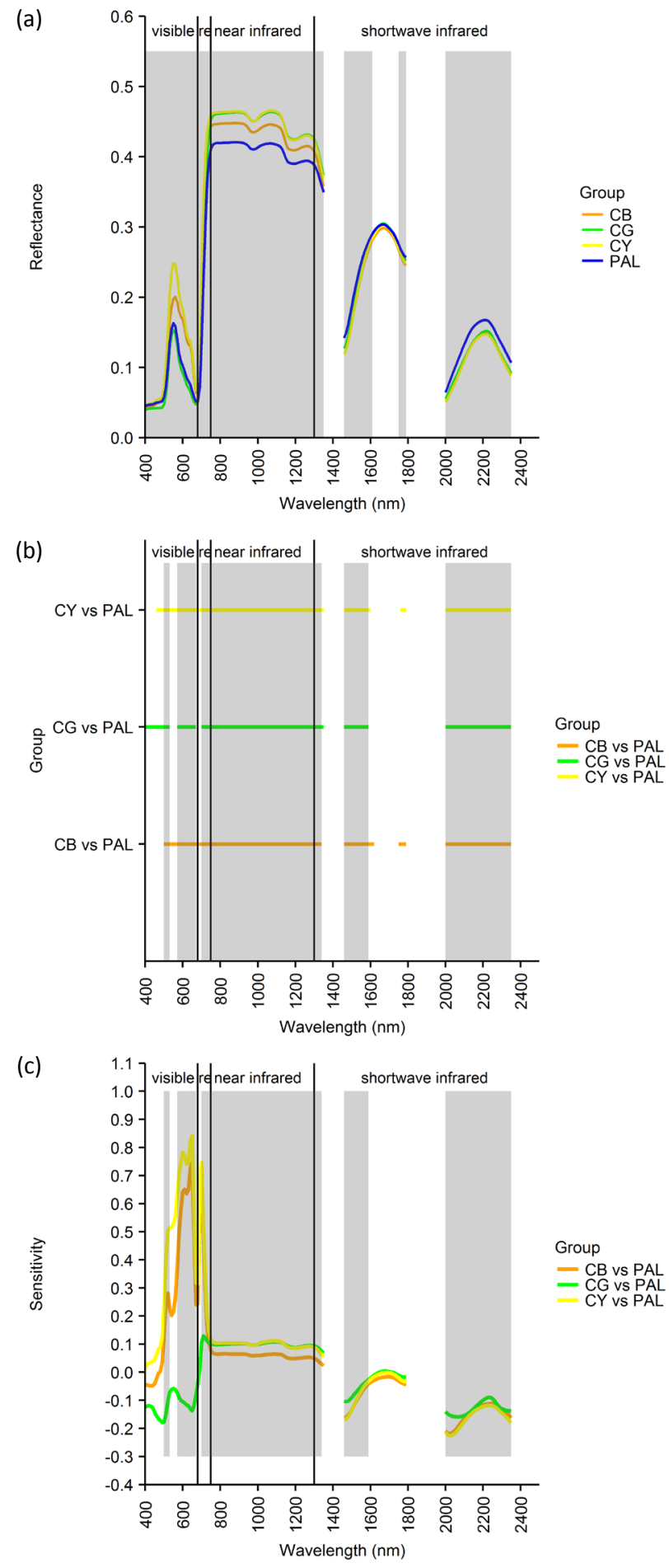

Figure 1. (a) 2015 mean reflectance $(n=24)$ values of cotton bronze $(C B)$, cotton green $(C G)$, cotton yellow (CY), and Palmer amaranth (PAL). Shaded area represents statistical significance $(p \leq 0.05)$ based on analysis of variance of treatment data. (b) Colored lines represent Dunnett's test results statistical significance difference $(p \leq 0.05)$ for PAL versus (vs) a specific cotton group. Shaded areas-statistically significant difference $(p \leq 0.05)$ between PAL and all of the cotton groups based on Dunnett's test results. (c) Sensitivity results of PAL versus (vs) the cotton groups. Shaded areas-same as 1(b). re-red edge. 

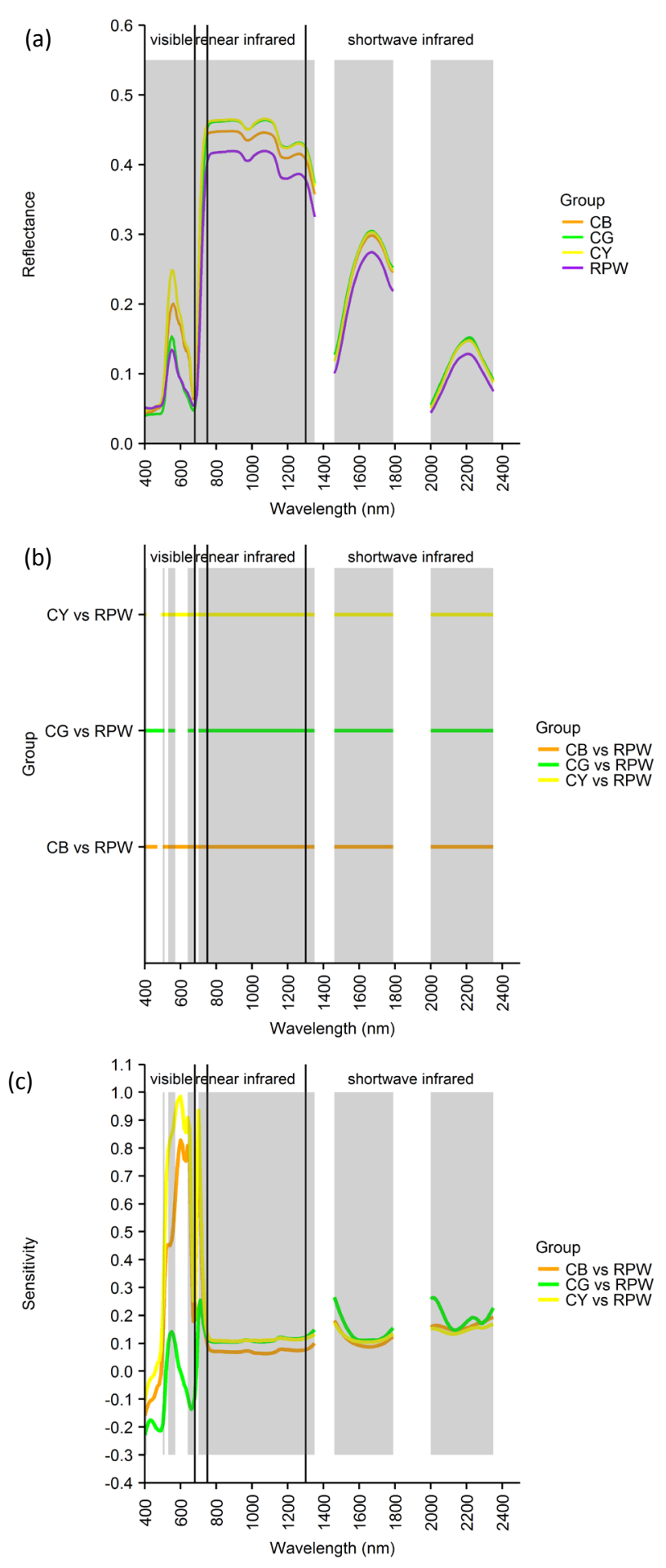

Figure 2. (a) 2015 mean reflectance $(n=24)$ values of cotton bronze (CB), cotton green $(C G)$, cotton yellow (CY), and redroot pigweed (RPW). Shaded area represents statistical significance ( $p \leq 0.05)$ based on analysis of variance. (b) Colored lines represent Dunnett's test results statistical significance difference $(p \leq 0.05)$ for RPW versus (vs) a specific cotton group. Shaded areas-statistically significant difference $(p \leq 0.05)$ between RPW and all of the cotton groups based on Dunnett's test results. (c) Sensitivity results of RPW versus (vs) the cotton groups. Shaded areas-same as 2(b). re-red edge. 

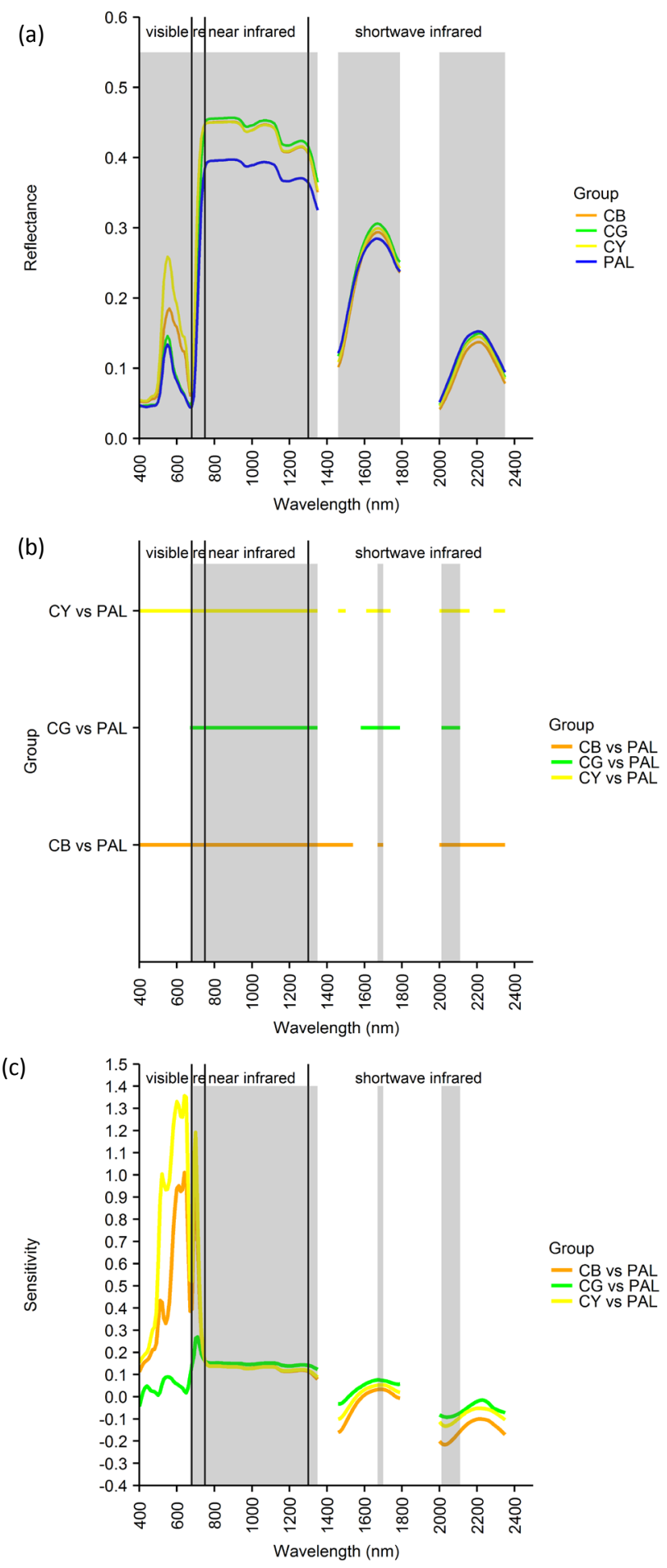

Figure 3. (a) 2016 mean reflectance $(n=24)$ values of cotton bronze $(C B)$, cotton green $(C G)$, cotton yellow (CY), and Palmer amaranth (PAL). Shaded area represents statistical significance ( $p \leq 0.05$ ) based on analysis of variance. (b) Colored lines represent Dunnett's test results statistical significance difference $(p \leq 0.05)$ for PAL versus (vs) a specific cotton group. Shaded areasstatistically significant difference $(p \leq 0.05)$ between PAL and all of the cotton groups based on Dunnett's test results. (c) Sensitivity results of PAL versus (vs) the cotton groups. Shaded areassame as (3b). re-red edge. 

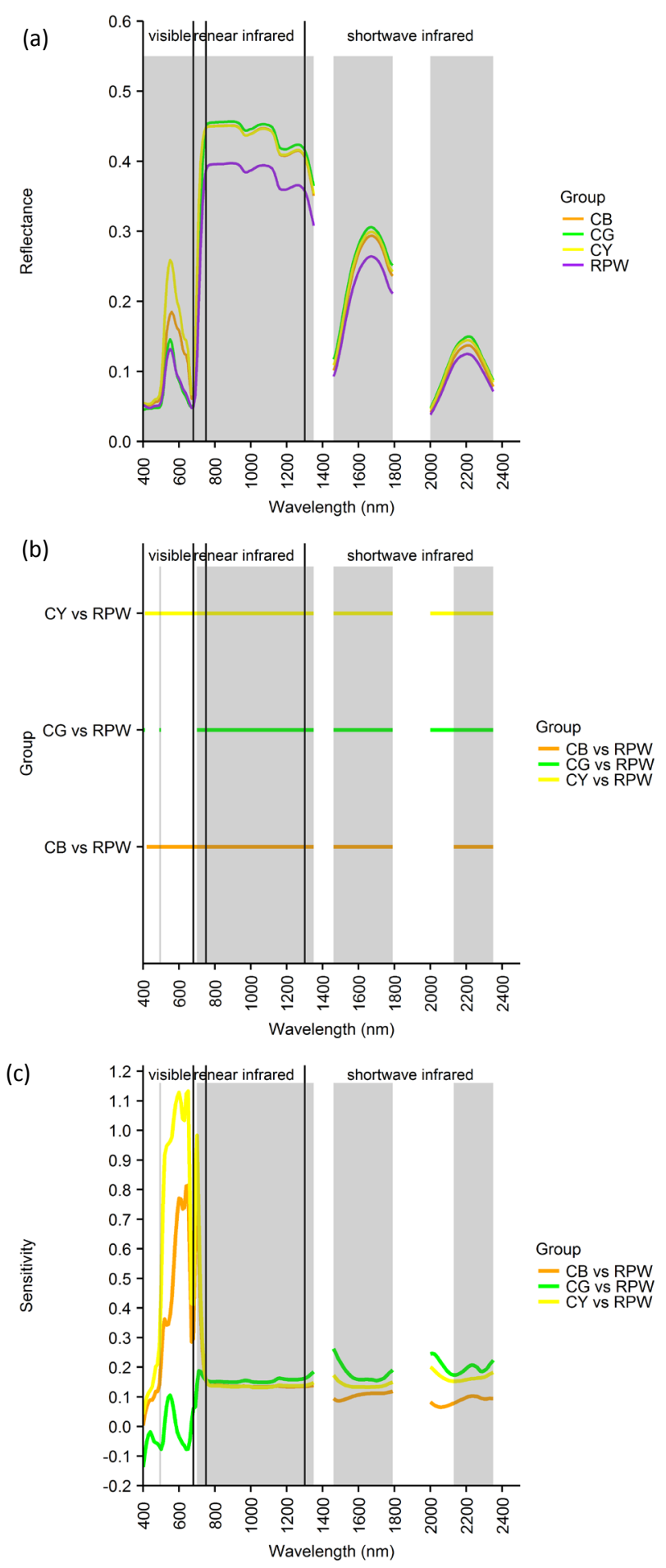

Figure 4. (a) 2016 mean reflectance $(n=24)$ values of cotton bronze (CB), cotton green $(C G)$, cotton yellow (CY), and redroot pigweed (RPW). Shaded area represents statistical significance ( $p \leq 0.05)$ based on analysis of variance. (b) Colored lines represent Dunnett's test results statistical significance difference $(p \leq 0.05)$ for RPW versus (vs) a specific cotton group. Shaded areas-statistically significant difference $(p \leq 0.05)$ between RPW and all of the cotton groups based on Dunnett's test results. (c) Sensitivity results of RPW versus (vs) the cotton groups. Shaded areas-same as 4(b). re-red edge. 
curves for both years. Also, noticeable reflectance differences occurred between the pigweeds and the cotton groups in the 800 to $1300 \mathrm{~nm}$ region of the spectrum. Furthermore, redroot pigweed spectral curves were readily separated from the cotton bronze, cotton green, and cotton yellow spectral curves in the 1600 to $1800 \mathrm{~nm}$ region of the spectrum. $92 \%$ (153 spectral bands) and 100\% (166 spectral bands) of the spectral bands were determined to be statistically significant (ANOVA, $p \leq 0.05$ ) for the Palmar amaranth-cotton and redroot pigweed-cotton datasets, respectively, in 2015. Statistically significant differences among groups were observed for all of the spectral bands in the 2016 datasets.

Spectral bands within the visible, red edge, near infrared, and shortwave infrared regions of the spectrum were useful for separating Palmer amaranth and redroot pigweed from a cotton group (Figure 1(b), Figure 2(b), Figure 3(b), Figure 4(b) colored lines, Dunnett's test, $p \leq 0.05)$. Optimal spectral bands for separating Palmer amaranth and redroot pigweed from cotton yellow and cotton bronze occurred in the 600 to $700 \mathrm{~nm}$ spectral range (Table 1, Figure 1(c), Figure 2(c), Figure 3(c), and Figure 4(c)). Peak sensitivity spectral bands of Palmer amaranth and cotton green were identified at 490 $\mathrm{nm}$ and $710 \mathrm{~nm}$ for the 2015 and 2016 datasets, respectively (Table 1). For both years, peak sensitivity was identified at $1460 \mathrm{~nm}$ spectral band for redroot pigweed versus cotton green (Table 1).

Gray shaded areas in Figures 1(b)-4(b) and Figures 1(c)-4(c) represent spectral regions where statistical significance in mean and sensitivity values was observed between a pigweed and all of the cotton groups (e.g., Palmer amaranth versus cotton bronze, Palmer amaranth versus cotton green, and Palmer amaranth versus cotton yellow). If the analyst is willing to accept some loss in sensitivity, the spectral waveband at approximately $710 \mathrm{~nm}$ could serve as a universal band for differentiating the pigweeds from the cotton plants.

Table 1. Peak sensitivity of Palmer amaranth and redroot pigweed discrimination from the cotton groups.

\begin{tabular}{ccc}
\hline Data collection date & Group & Peak sensitivity spectral band \\
\hline June 5, 2015 & Palmer amaranth-cotton bronze & $650 \mathrm{~nm}$ \\
& Palmer amaranth-cotton green & $490 \mathrm{~nm}$ \\
& Palmer amaranth-cotton yellow & $650 \mathrm{~nm}$ \\
& Redroot pigweed-cotton bronze & $700 \mathrm{~nm}$ \\
& Redroot pigweed-cotton green & $1460 \mathrm{~nm}$ \\
& Redroot pigweed-cotton yellow & $600 \mathrm{~nm}$ \\
\hline June 3, 2016 & Palmer amaranth-cotton bronze & $640 \mathrm{~nm}$ \\
& Palmer amaranth-cotton green & $710 \mathrm{~nm}$ \\
& Palmer amaranth-cotton yellow & $640 \mathrm{~nm}$ \\
& Redroot pigweed-cotton bronze & $650 \mathrm{~nm}$ \\
& Redroot pigweed-cotton green & $1460 \mathrm{~nm}$ \\
& Redroot pigweed-cotton yellow & $650 \mathrm{~nm}$ \\
\hline
\end{tabular}




\section{Discussion}

The leaf hyperspectral results support using a multispectral approach to distinguish Palmer amaranth and redroot pigweed from cotton near-isogenic lines with bronze, green, or yellow leaves (Table 1, Figure 1(c), Figure 2(c), Figure 3(c), and Figure 4(c)). Spectral data within the 600 to $700 \mathrm{~nm}$ range was deemed the most sensitive for differentiating Palmer amaranth and redroot pigweed from cotton bronze and cotton yellow. Chlorophyll and carotenoids affect plant leaves reflectance properties in the 600 to $700 \mathrm{~nm}$ region of the light spectrum. Chlorophyll strongly absorbs blue (400 to 500 $\mathrm{nm}$ ) and red light (600 to $670 \mathrm{~nm}$ ) and moderately reflects green light (500 to $600 \mathrm{~nm}$ ), resulting in masking of other plant pigments in green leaves. Cotton bronze and cotton yellow plants were designed to have lower chlorophyll levels, thus increasing spectral reflectance of the cotton leaves in the 600 to $700 \mathrm{~nm}$ region of the spectrum and allowing other pigments to be seen. Research findings have indicated that it was best to detect yellow to brown foliage in the $680 \mathrm{~nm}$ spectral range regardless of the plant stress [15] [17]. The current study did not focus on plant stress per se; nevertheless, the foliage of the cotton plants was yellow green to bronze in color, thus resulting in wavelengths of peak sensitivity being close to the $680 \mathrm{~nm}$ spectral range (Table 1).

The red edge region, ranging from $680-760 \mathrm{~nm}$, is a transitional zone between red and near infrared light reflectance [18] [19]. Therefore, leaf reflectance is a combined response of chlorophyll absorption and internal scattering associated with leaf structure in the red and near infrared regions of the light spectrum, respectively. Increases in chlorophyll cause the red edge region to shift towards shorter wavelengths and vice versa for decreases in chlorophyll content. It was speculated that differences in chlorophyll content caused shifts in the red edge region of the spectrum, leading to the sensitivity peak observed at $700 \mathrm{~nm}$ and $710 \mathrm{~nm}$ for the 2015 redroot pigweed versus cotton bronze and for the 2016 Palmer amaranth versus cotton green datasets, respectively (Figure 2(c), Figure 3(c)). It is also important to note that the $710 \mathrm{~nm}$ spectral band maintained its consistency from year to year for the Palmer amaranth versus cotton green dataset, suggesting it was a more reliable band to use compared with the $490 \mathrm{~nm}$ spectral band selected for 2015. Finally, the red edge band at $710 \mathrm{~nm}$ has strong potential to serve as a universal band for cotton weed discrimination. With this band, the analyst would compromise some sensitivity. However, only a single sensor tuned into that region of the spectrum would be needed for pigweed and cotton separation.

The shortwave infrared region $(1300-2500 \mathrm{~nm})$ of the spectrum is affected by water content in plants [11] [20] [21] [22]. The sensitivity peak identified in the $1460 \mathrm{~nm}$ region of the spectrum for redroot pigweed leaves versus cotton green leaves suggested that redroot pigweed leaves had a higher water content than cotton green leaves (Figure 2(c), Figure 4(c)). [23] also indicated that the shortwave infrared region of the spectrum was useful for weed crop discrimination, and [11] indicated the importance of shortwave infrared data for vegetation mapping and crop separation.

All of the cotton groups were readily distinguishable from the pigweeds in the near infrared regions of the spectrum (Figure 1(a), Figure 2(a), Figure 3(a), Figure 4(a)); 
however, the sensitivity scores of the near infrared spectral bands were intermediate or less than the sensitivity scores of spectral data in other regions of the spectrum (Figure 1(c), Figure 2(c), Figure 3(c), Figure 4(c)). Nevertheless, a band selected from that region of the spectrum would provide additional information related to leaf structure [22] to distinguish Palmer amaranth and redroot pigweed from cotton. Any band within the 770 to $1290 \mathrm{~nm}$ spectral range would suffice.

Pure leaf spectra and not canopy spectra were used in this study. Therefore, some differences will exist in spectral data collected at the canopy level, which is affected by in-canopy shadowing, leaf orientation, and differences in leaf area. However, the findings provided basic information on leaf reflectance properties of the cotton versus the two pigweeds and on the spectral regions for their differentiation. Additionally, this was the first study in which cotton leaves with different colors were distinguished from Palmer amaranth and redroot pigweed, two troublesome weeds in cotton production systems.

\section{Conclusion}

Hyperspectral data are effective for developing spectral profiles for pigweeds and cotton, leading to the identification of spectral bands to use on sensors for pigweed cotton discrimination. Optimal spectral bands for pigweed and cotton separation were observed in the 600 to $700 \mathrm{~nm}$ spectral range (both weeds versus cotton bronze and cotton yellow), and at $710 \mathrm{~nm}$ (Palmer amaranth versus cotton green) and $1460 \mathrm{~nm}$ (redroot pigweed versus cotton green). Commercially available cameras can collect data in the wavelengths identified in this study, thus supporting remote sensing as a survey tool for differentiating cotton from Palmer amaranth and redroot pigweed.

\section{Acknowledgements}

The authors are grateful to Dr. Vijay Nandula for supplying the pigweed seed and Milton Gaston, Jr., Keysha Hamilton, Arrington Richardson, Arrington Smith, Michael Fisher, Destraile Jackson, Ra Kaiyah Myles, and David Fisher for their assistance in data collection. Mention of trade names or commercial products in this report is solely for the purpose of providing specific information and does not imply recommendation or endorsement by the US Department of Agriculture.

\section{References}

[1] Rowland, M.W., Murray, D.S. and Verhalen, L.M. (1999) Full-Season Palmer Amaranth (Amaranthus palmeri) Interference with Cotton (Gossypium hirsutum). Weed Science, 47, 305-309.

[2] Morgan, G.D., Baumann, P.A. and Chandler, J.M. (2001) Competitive Impact of Palmer Amaranth (Amaranthus palmeri) on Cotton (Gossypium hirsutum) Development and Yield. Weed Technology, 15, 408-412. http://dx.doi.org/10.1614/0890-037X(2001)015[0408:CIOPAA]2.0.CO;2

[3] Fast, B.J., Murdock, S.W., Farris, R.L., Willis, J.B. and Murray, D.S. (2009) Critical Timing of Palmer Amaranth (Amaranthus palmeri) Removal in Second-Generation Glyphosate- 
Resistant Cotton. Journal of Cotton Science, 13, 32-36.

[4] MacRae, A.W., Webster, T.M., Sosnoskie, L.M., Culpepper, A.S. and Kichler, J.M. (2013) Cotton Yield Loss Potential in Response to Length of Palmer Amaranth (Amaranthus palmeri) Interference. Journal of Cotton Science, 17, 227-232.

[5] Flessner, M., Frame, H. and Holshouser, D. (2015) Prevention and Control of Palmer Amaranth in Cotton. Virginia Polytechnic Institute and State University. 2805-1001 (PPWS-60NP).

[6] Buchanan, G.A. and Burns, E.R. (1971) Weed Competition in Cotton. II. Cocklebur and Redroot Pigweed. Weed Science, 19, 580-582.

[7] Thorp, K. and Tian, L. (2004) A Review on Remote Sensing of Weeds in Agriculture. Precision Agriculture, 5, 477-508. http://dx.doi.org/10.1007/s11119-004-5321-1

[8] Smith, A.M. and Blackshaw, R.E. (2003) Weed-Crop Discrimination Using Remote Sensing: A Detached Leaf Experiment. Weed Technology, 17, 811-820.

http://dx.doi.org/10.1614/WT02-179

[9] Koger, C.H., Shaw, D.R., Reddy, K.N. and Bruce, L.M. (2004) Detection of Pitted Morningglory (Ipomoea lacunosa) with Hyperspectral Remote Sensing. II. Effects of Vegetation Ground Cover and Reflectance Properties. Weed Science, 52, 230-235. http://dx.doi.org/10.1614/WS-03-083R1

[10] Peña-Barragãn, J.M., López-Granados, F., Jurado-Expósito, M. and Garciá-Torres, L. (2006) Spectral Discrimination of Ridolfia segetum and Sunflower as Affected by Phenological Stage. Weed Research, 46, 10-21. http://dx.doi.org/10.1111/j.1365-3180.2006.00488.x

[11] Thenkabail, P.S., Gumma, M.K., Teluguntla, P. and Mohammed, I.A. (2014) Hyperspectral Remote Sensing of Vegetation and Agricultural Crops. Photogrammetric Engineering and Remote Sensing, 80, 697-709.

[12] Thenkabail, P.S., Smith, R.B. and De Pauw, E. (2000) Hyperspectral Vegetation Indices and Their Relationships with Agricultural Crop Characteristics. Remote Sensing of Environment, 71, 158-182. http://dx.doi.org/10.1016/S0034-4257(99)00067-X

[13] Lehnert, L.W., Meyer, H. and Bendix, J. (2016) Hsdar: Manage, Analyse and Simulate Hyperspectral Data in R. R Package Version 0.4.1.

[14] R Core Team (2015) R: A Language and Environment for Statistical Computing. R Foundation for Statistical Computing, Vienna, Austria. https://www.R-project.org/

[15] Carter, G.A., Dell, T.R. and Cibula, W.G. (1996) Spectral Reflectance Characteristics and Digital Imagery of a Pine Needle Blight in the Southeastern United States. Canadian Journal of Forest Research, 26, 402-407. http://dx.doi.org/10.1139/x26-045

[16] Hothorn, T., Bretz, F. and Westfall, P. (2008) Simultaneous Inference in General Parametric Models. Biometrical Journal, 50, 346-363. http://dx.doi.org/10.1002/bimj.200810425

[17] Carter, G.A. (1991) Primary and Secondary Effects of Water Content on the Spectral Reflectance of Leaves. American Journal of Botany, 78, 916-924. http://dx.doi.org/10.2307/2445170

[18] Gates, D.M., Keegan, H.J., Schleter, J.C. and Weidner, V.R. (1965) Spectral Properties of Plants. Applied Optics, 4, 11-20. http://dx.doi.org/10.1364/AO.4.000011

[19] Horler, D.N.H., Dockray, M. and Barber, J. (1983) The Red Edge of Plant Leaf Reflectance. International Journal of Remote Sensing, 4, 273-288. http://dx.doi.org/10.1080/01431168308948546

[20] Tucker, C.J. (1980) Remote Sensing of Leaf Water Content in the Near Infrared. Remote Sensing of Environment, 10, 23-32. http://dx.doi.org/10.1016/0034-4257(80)90096-6 
[21] Gausman, H.W. (1985) Plant Leaf Optical Properties in Visible and Near Infrared Light. Graduate Studies, Texas Tech University (No. 29). Texas Tech Press, Lubbock.

[22] Sahoo, R.N., Ray, S.S. and Manjunath, K.R. (2015) Hyperspectral Remote Sensing of Agriculture. Current Science, 108, 848-859.

[23] Gray, C.J., Shaw, D.R. and Bruce, L.M. (2009) Utility of Hyperspectral Reflectance for Differentiating Soybean (Glycine max) and Six Weed Species. Weed Technology, 23, 108-119. http://dx.doi.org/10.1614/WT-07-117.1

Submit or recommend next manuscript to SCIRP and we will provide best service for you:

Accepting pre-submission inquiries through Email, Facebook, LinkedIn, Twitter, etc. A wide selection of journals (inclusive of 9 subjects, more than 200 journals)

Providing 24-hour high-quality service

User-friendly online submission system

Fair and swift peer-review system

Efficient typesetting and proofreading procedure

Display of the result of downloads and visits, as well as the number of cited articles

Maximum dissemination of your research work

Submit your manuscript at: http://papersubmission.scirp.org/

Or contact ajps@scirp.org 